\title{
The Multi-Center Dilemma Project: An Investigation on the Role of Cognitive Conflicts in Health
}

\author{
Guillem Feixas ${ }^{1}$ and Luis Ángel Saúl ${ }^{2}$ \\ ${ }^{1}$ University of Barcelona \\ ${ }^{2}$ Open University (UNED)
}

\begin{abstract}
The Multi-Center Dilemma Project is a collaborative research endeavour aimed at determining the role of dilemmas - a kind of cognitive conflict, detected by using an adaptation of Kelly's Repertory Grid Technique - in a variety of clinical conditions. Implicative dilemmas appear in one third of the non-clinical group $(n=321)$ and in about half of the clinical group $(n=286)$, the latter having a proportion of dilemmas that doubles that of the non-clinical sample. Within the clinical group, we studied 87 subjects, after completing a psychotherapy process, and found that therapy helps to dissolve those dilemmas. We also studied, independently, a group of subjects diagnosed with social phobia $(n=13)$ and a group diagnosed with irritable bowel syndrome $(n=13)$ in comparison to non-clinical groups. In both health related problems, dilemmas seem to be quite relevant. Altogether, these studies, though preliminary (and with a small group size in some cases), yield a promising perspective to the unexplored area of the role of cognitive conflicts as an issue to consider when trying to understand some clinical conditions, as well as a focus to be dealt with in psychotherapy when dilemmas are identified.

Keywords: cognitive conflict, repertory grid technique, personal construct theory, social phobia, irritable bowel syndrome
\end{abstract}

\begin{abstract}
El Proyecto Multi-Céntrico Dilema aúna los esfuerzos de distintos centros de investigación con el propósito de determinar el papel de los dilemas personales en una amplia gama de problemas de salud. Estos dilemas, identificados mediante una adaptación de la Técnica de Rejilla de Kelly, aparecen en un tercio de un grupo de población normal ( $\mathrm{n}$ = 321) y en la mitad del grupo clínico $(n=286)$. Comparando los sujetos que presentan dilemas, los del grupo clínico doblan a los del grupo normal en proporción de dilemas. También revisamos dos estudios independientes con un grupo de pacientes diagnosticados con fobia social $(n=13)$ y otro con síndrome del intestino irritable $(n=13)$, ambos en comparación con grupos de población normal. En los dos casos se encuentran diferencias que apuntan en la dirección de la relevancia de los dilemas. Tomando en conjunto los datos disponibles, todo parece augurar unas buenas perspectivas con respecto al papel relevante (auque hasta el momento no explorado) de los conflictos cognitivos a la hora de comprender algunos problemas clínicos. También sugieren el interés de incluir en su tratamiento el trabajo con dilemas, al menos para los sujetos que los presenten.

Palabras clave: conflicto cognitivo, técnica de rejilla, teoría de los constructos personales, fobia social, síndrome del intestino irritable
\end{abstract}

This work was partially supported by the Ministry of Science and Technology of Spain Research grant BSO2000-0661. We are also grateful to the Departament de Personalitat, Avaluació i Tractament Psicològics at the Universitat de Barcelona for their support.

Correspondence concerning this article should be addressed to Guillem Feixas, Departament de Personalitat, Avaluació i Tractament Psicològics. Universitat de Barcelona. Passeig vall d’Hebron, 171. 08035 Barcelona (Spain). Fax: 0034934021 362. E-Mail: gfeixas@ub.edu 
The Multi-Center Dilemma Project (MDP) was launched as a research project in 1999 to investigate the role of dilemmas in different mental and physical health problems, and to devise and implement therapeutic methods focused on resolving those dilemmas (see more details in Feixas, Saúl, Ávila-Espada, \& Sánchez, 2001; Feixas, Saul, \& Sánchez, 2000; and on the Internet: www.usal.es/tcp). Currently, various Universities and clinical centers, mainly from Spain but also from the United Kingdom, Portugal, Italy and South America, are involved, at different levels, in this project.

Despite their relevance in many problems involving decision making, the notions of cognitive conflicts and dilemmas are scarcely investigated. Psychoanalytical theories use the notion of conflict to refer to the internal dynamics of the psyche. Piaget (e.g., 1975) uses the term "cognitive conflict" to refer to the contradictions the child encounters when trying to explain events. These conflicts cause disequilibrium, and the child is forced to reorganize his intellectual processes in order to rid him or herself of the conflict which is causing the trouble; hence the consequent intellectual change. Also, social cognitive theorists such as Heider (1946) and Festinger (1957), with their theories of balance and cognitive dissonance respectively, dealt with the issue of lack of internal consistency. These theories postulated a tendency to avoid contradictory cognitions about social reality. However, the tension arising from imbalanced, incongruent or dissonant beliefs is conceived as a motivational force in human behavior. Cognitive balance or congruity has been shown to be related to a variety of social decision making theories. Thus, although these dissonances or conflicts are recognized to be unpleasant experiences, they have not been related to unhealthy states or psychopathology. On the contrary, cognitive conflicts are seen as a central aspect of human motivation and growth (Feixas, 2002).

One of the major problems of these theories about cognitive conflicts is finding a way to define them in operational terms. That is, certainly, a crucial issue for the development of research programs to investigate the nature and influence of cognitive conflicts on human behavior.

In sum, it can be argued that the notion of cognitive conflict is central to human functioning, as recognized by various psychological theories, even though the internal nature of conflict makes it difficult to identify and measure. For the most part, the notion of cognitive conflict must be formulated in the context of a wider psychological theory capable of providing more specific terms and instruments to assess it.

Our research program, the MDP, is based on Kelly's (1955, 2001) Personal Construct Psychology (PCP), a constructivist theory that understands human functioning as based on the meaning we ascribe to events (Botella \& Feixas, 1998; Feixas \& Villegas, 2000). The interest of a constructivist orientation in clinical and health psychology lies in its focus on the subjective meaning people give to themselves, others and the events they encounter (this includes their problems as well as interventions provided by professionals). Since the idea is that people do not react to stimuli, but to the way they interpret them, methods of conducting a systematic and careful study of the subject's interpretations seem clearly relevant both for research and clinical practice (Feixas, 2003). In effect, the interventions devised for a particular situation will also have to be elaborated by the very same subject. That is, patients (or consultants) will react to them depending on how they assimilate the interventions within their construction system (i.e., complying/agreeing with them or resisting them, see Feixas, Sánchez, Laso, \& Gómez-Jarabo, 2002).

Similar to other constructivist theories, in PCP the individual is seen as continuously interpreting events in terms of his or her cognitive system, and revising it as a scientist would do. This system is formed by a set of bi-polar personal constructs with multiple inter-relationships. The cognitive conflicts, in this context, are identified as particular construct arrangements that lead to contradicting actions or dispositions.

We have devised a method to identify those conflicts using the Repertory Grid Technique (RGT). As summarized in Appendixes 1 and 2, the RGT is one of the more commonly used instruments for investigating an individual's personal construction system (it can be used in families and groups as well). Our interest is to explore the role of these conflicts in various clinical or health related conditions. We have completed some preliminary studies in the areas of social phobia (Díaz, Feixas, Pellungrini, \& Saúl, 2001), irritable bowel syndrome (Benasayag, Feixas, \& Mearín, 2002; Benasayag, Feixas, Mearin, Saúl, \& Laso, 2004), and menopause (Lucero, Feixas, \& Saúl, 2003). We are also collecting data in the areas of depression and agoraphobia.

\section{Personal Constructs, Cognitive Conflicts, and Symptoms}

As it is central to constructivist approaches (Feixas \& Villegas, 2000), PCP views human activity as a meaning creating process (for an extensive account of PCP, see Botella \& Feixas, 1998; Kelly, 1955, 2001). How human organisms behave is dependant on the way they construe events and in turn, assign meaning to those events.

For Kelly, humans are scientists who construct theories about themselves and the world. While formal theories are made out of theoretical constructs, each person, creates his or her own system of personal constructs to interpret and anticipate events.

Personal constructs are distinctions drawn from experience and thus incorporated into the construction system to anticipate future events. Each construct entails a difference, and can be represented as a bi-polar dimension of meaning, such as "beautiful-ugly". Many distinctions, however, are pre-verbal and remain without a label in the personal construction system. Constructs are not isolated units but are connected with others by implication lines, thus forming a complex system of meanings. For example, for a given subject the construct 
"extraverted-introverted"1 may be linked to the construct "competent-incompetent", so that being extraverted implies being competent as well. However, for another subject, extraverted may not imply competence but mainly "being the protagonist" versus "remaining unnoticed" in the group.

The personal construction system is organized as a hierarchical network of constructs. Some of these constructs are very concrete and serve as kind of operational definitions of higher order constructs. For example, "being able to talk to an audience-unable to talk in public" might be, for a given subject, an operational definition of the super-ordinate construct "secure-insecure". Some of these high order constructs form the core of the system, that is, his or her personal sense of identity. Changing those constructs will be resisted because it would imply alterations in the whole system, and a threat to the personal identity of the subject.

Since personal construction systems are idiosyncratic, both in their content and structure (implication lines among constructs,), PCP has devised methods for studying them for each individual. Understanding an individual's construction system is necessary to predict which changes can be made and which might be resisted. Changes in the system involving a change in the sense of identity will inevitably take more time. Other constructs have to be incorporated within the system as well.

Symptoms (anxiety, depression, fear, avoidant behaviors, etc.) are a painful, but integral part of human activity. They challenge many theoretical and everyday concepts regarding human behavior. From a PCP perspective, however, they are not an exception to the laws of behavior, or an error of nature, but activities embedded in an interpretation process. When the constructs are invalidated during the flow of experience, emotions may appear until the subject has revised his or her personal construction system.

PCP has elaborated several hypotheses for understanding symptoms as related to the construal process. For example, Fransella (1970), in her study with individuals who stutter, suggested that symptoms could end up being a way of life for the client by becoming a central structure in his/her construction system or identity. In this situation, abandoning the symptoms would involve abandoning a core meaning structure which could be essential for making sense of oneself and the world. Lack of predictability within the construction system would be experienced as anxiety by the person. According to Kelly (1955), "even an obviously invalid part of a construction system may be preferable to the void of anxiety which might be caused by its elimination altogether" (p. 831).
Another hypothesis derived from PCP regarding understanding symptoms as related to meaning, focuses on the idea of conflict. We can differentiate two types of cognitive conflicts: implicative dilemmas and dilemmatic constructs.

\section{Implicative Dilemmas}

For some clients, symptom loss, while desirable, may carry negative implications. That is, construing the self with a symptomatic pole of a construct is a way of maintaining their present position in positive poles of other, more central, constructs. This is because the symptomatic construct for which the change is desirable, is linked, through their construction system, to other constructs for which change is not desirable and would involve considerable threat. For example, Winter $(1988,1989)$ studied clients with social anxiety problems for whom social competence carried negative implications, and the more pronounced these implications, the more negative the outcome in social skills training groups. He suggests that improvement or symptom reduction may confront these clients with guilt (Winter, 1989), which Kelly described as the experience of dislodgement from one's core role (our way of relating to others).

We have described (Feixas, Saúl, Avila-Espada, \& Sánchez, 2001; Feixas, Saul, \& Sánchez, 2000; Feixas \& Saúl, 2002) a way of identifying implicative dilemmas from the RGT which has been implemented in the RECORD/GRIDCOR (see footnote 5 in Appendix 2) program version 4.0 (Feixas \& Cornejo, 2002). In this way, two different types of constructs are differentiated; discrepant and congruent. The former type refers to those constructs from which the subject rates the self now and the ideal self at different ends of the construct poles. For example, on a 7-point Likert scale, the difference would have to be greater than 3 points to meet the criteria for a discrepant construct. A difference of less than 2 would be considered as a congruent construct, i.e. the subject rates the self now and ideal self elements similarly.

Discrepant constructs (e.g., timid vs. sociable) indicate areas of dissatisfaction for the individual, areas in which the subject would like to experience substantial change. Often, they represent symptomatic aspects of the person. Conversely, congruent constructs (e.g., modest vs. arrogant) reveal areas of satisfaction for the subject. They refer to personal qualities (i.e., modesty) that are not felt to require change, in fact, the subject may even be proud of them. The dilemma appears when the desired change in a discrepant construct (becoming sociable) implies an undesired change (i.e., becoming arrogant) in a congruent construct (as measured by a correlation between

1 Note that here "extraverted-introverted" is a personal construct, not a theoretical construct. While the latter is defined within the context of a given personality theory (e.g. Eysenck's), when considered as a personal construct it has to be interpreted according to the meaning the particular subject in case gives to the term. That personal meaning can be best understood by exploring the implication lines that the construct "extraverted-introverted" has with the other constructs of his or her personal construction system. 
these two constructs, set up at the minimum level of 0.20 , for clinical practice, or at the level of 0.35 in our research studies). In PCP, the term implicative dilemmas is used to refer to this type of conflict because the dilemma is caused by the implication lines among constructs, that is, the way constructs are linked in the construction system (see Figure 2 for a graphic disposition). In the example above, "sociable" implies "arrogant" and "timid" implies "modest."

To offer a case illustration, we analyzed Teresa's grid (see Appendix 1 and Figure 1) and we identified two implicative dilemmas related to her depressive symptoms (see Figure 3).

The patient associates the construct pole "does not get depressed easily" with two construct poles that she considers opposite her self-definition:

To be "selfish" (vs. being concerned about others).

To be the kind of person that "pretends to be stronger than one is" (vs. being natural).

The aim of therapy (as described in Feixas \& Saúl, in press) was to sever these associations, as at present, they were preventing the client from forming alternative definitions of her self, i.e. as a person who does not get depressed easily. As a consequence of implicative dilemma resolution, the client would be alleviated of her depressive symptoms.

According to our therapeutic hypothesis, we should help the patient to elaborate, in alternative ways, the implications of her constructs and to facilitate a wider perspective in which to view herself. Loosening the implications of her constructs would help Teresa to see herself as a person who is natural, concerned about others, (the opposite of a "selfish" person and one who pretends "to be stronger than one is") while at the same time "does not get depressed easily."

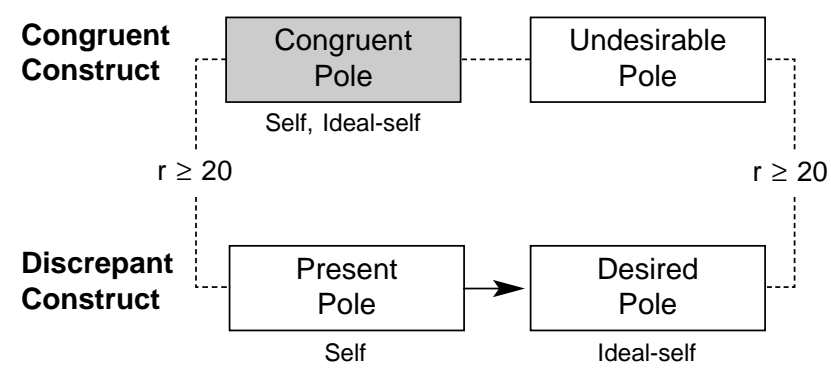

Figure 2. Basic structure of an implicative dilemma derived from repertory grid data.

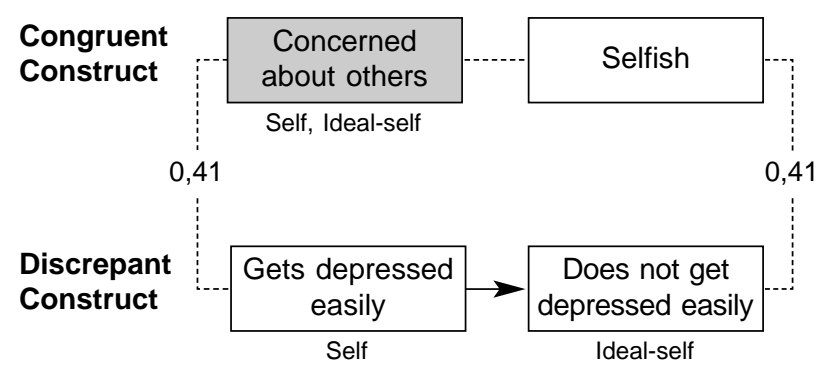

Figure 3. Implicative dilemmas identified in Teresa's initial grid.
The period of time between the first and the last grid was only four months. Therapy had to end just before the academic holidays, so we didn't have much time to work. However, the patient began to show signs of elaboration (expansion) of some of her constructs. She started to appreciate that "concern about others" also implies concern about oneself. Thus, the construct became more permeable so as to include the self among the range of its elements. Probably, as a consequence of this reconstruction, the client's psychological well being was enhanced, and therefore her depression reduced, as denoted by the assessment at the end of therapy.

The improvements at the symptomatic level were accompanied by changes in Teresa's construing. The correlations between the constructs involved in the two implicative dilemmas described before, decreased to 0.22 and 0.16 respectively, indicating a change in the direction of dilemma resolution or dissolution.

\section{Dilemmatic Constructs}

A dilemmatic construct is one which does not offer a clear course of action. Constructs are bi-polar meaning structures, and, according to Kelly's (1955, 2001) choice corollary, the person chooses for him or herself the pole of the construct that permits greater elaboration of the system, that is, the one which increases its predictive power (or, at least, decreases the unpredictability of events). For some constructs, both poles are considered as undesirable by the subject, or he or she may be ambivalent, as each pole has both advantages and disadvantages. The person, therefore, may not be able to choose between the alternatives represented by either construct pole.

In the context of the RGT, we identify a dilemmatic construct by a middle-point score on the ideal self element. That is, the person does not wish to be either of the two poles of the construct. For example, in the construct "talkativereserved" the person rates a 4 for his or her ideal self. This score means that he or she does not wish to be talkative or reserved. Both of the options may involve advantages and disadvantages. Being talkative might be useful in facilitating the ease of social interactions but it may also carry the implication of being superficial or boring. The person may not perceive either of the two alternatives as desirable and may therefore remain in the middle-point of the scale.

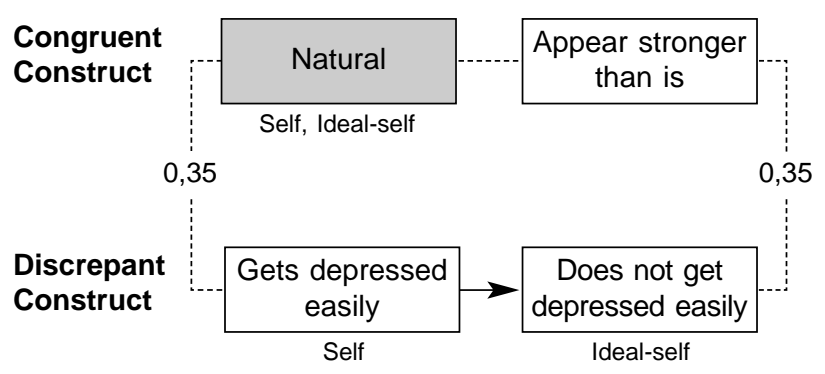


If many dilemmatic constructs appear in a subject's grid, it means we can hypothesize that he or she has not developed meaningful constructions which are viable or useful to him or her. This condition may manifest itself in feelings of insecurity, hesitation or lack of action. The person may not know in which direction to go, rather he or she may know where to avoid going, and may consequently adopt a potentially uncertain or reluctant attitude towards actions involved with those constructs.

\section{Some Preliminary Research Data}

What follows is a review of some of the studies which have recently been conducted. The different research centers participating in the MDP provide a central database with data regarding their subjects, then these data are used for different studies. As these are ongoing projects, the studies themselves need more refinements, (which we are in the process of doing), and more areas are presently being studied, but no results or publications have been produced yet.

\section{Descriptive Data Comparing Clinical and Non-Clinical Groups}

Our first data report (Feixas \& Saul, 2003) on the general status of the MDP database shows that implicative dilemmas can be identified in the grids of one third (34\%) of a non clinical group of 321 subjects recruited by psychology students after some training in grid administration and analysis. In a clinical group of 286 psychotherapy clients presenting with a wide variety of clinical problems (excluding psychosis or problems involving severe brain damage or disability), dilemmas appear in more than one half $(52.4 \%)$ of the group. This difference proved to be significant using a chi-squared test.

To further investigate the number of dilemmas appearing in each group (among those subjects who presented at least one), we used the Percentage of Implicative Dilemmas (PID) measure $^{2}$. The clinical group $(4.37 \%)$ had double the number of dilemmas than the non-clinical group $(2.11 \%)$, a significant difference.
Despite the differences found with respect to implicative dilemmas, no noticeable differences were found with respect to dilemmatic constructs.

In sum, these exploratory results indicate that:

a) The presence of dilemmas, as shown by repertory grids, is a common and natural situation in humans, at least to some degree.

b) Subjects in consultation for clinical problems are more likely to present dilemmas than subjects who aren't.

c) Grids of subjects presenting with psychological symptoms yield a greater number of dilemmas.

Points (b) and (c) suggest that dilemmas are related to psychological distress, but point (a) cautions us against considering dilemmas as a pathological sign. Altogether, our research seems to suggest that dilemmas are a part of life but, when not addressed, or when excessive in number (and maybe in intensity), they can be associated with suffering and pathology. This can be seen as an argument in favor of the idea that there is not a distinct line distinguishing between "normal" and "pathological" subjects. Maybe we, as humans, develop symptoms when, among many other reasons, the dilemmas we face are excessive, or we feel that we are "in over our heads" (Kegan, 1994).

\section{Some Data on Social Phobia}

As mentioned before, the area of social anxiety was one of the first areas to be investigated with respect to the presence of dilemmas. However, no systematic and well defined criteria to identify dilemmas had been used before. We conducted a study (Díaz et al., 2001) with a small number ( $n=13,9$ male, 4 female) of participants who had been diagnosed with social phobia, and compared them to a non-clinical group of 224 subjects in terms of their cognitive conflicts.

Results of the comparison can be found in Table 1. Three levels of conflict were established. The grids for subjects in the "no conflict" level ( $8 \%$ of the clinical and $20 \%$ of the non-clinical groups) did not yield either implicative dilemmas or dilemmatic constructs. The grids in the "moderate conflict" level show either implicative dilemmas (23\% clinical, $17 \%$ non-clinical) or dilemmatic constructs (23\% clinical, $43 \%$ non-clinical). Those with both types of conflicts $(46 \%$ of the

2 Although the number of dilemmas in a given grid would seem an obvious measure, we have found, in a pilot study, that the amount of dilemmas may increase with grid size. Therefore, as grid size is not standardized, grids cannot be reliably compared.

$$
\mathrm{PID}=\frac{d}{(n ! / 2 \cdot[(\mathrm{n}-2) !])} \times 100
$$

$d=$ number of dilemmas

$n=$ number of constructs in the grid

PID = Percentage of Implicative Dilemmas

A method was devised to compensate for this problem which takes into account the number of constructs in the grid. The number of possible pairs of constructs was calculated and used as the denominator in the formula. The result of this equation is multiplied by 100 , in order to establish the percentage (PID). 
clinical group vs. $20 \%$ of the non-clinical group) were considered "high conflict". Looking at the clinical group, only $8 \%$ (one subject) could be placed at the "no conflict" level while $46 \%$ were classified within the "high conflict" category. Overall, implicative dilemmas help to discriminate better between clinical (69\%) and non-clinical groups (37\%) than dilemmatic constructs. When looking at the number of implicative dilemmas, the average for those presenting with this type of conflict was much higher for the clinical group (9.92; $S D=14.9)$ than for the non-clinical group $(1.65 ; S D$ $=3.4$ ). Although no statistical significance was computed for these data because of the small size of the data, some trends seem clearly promising, making future investigations with bigger groups a worthy investment.

Our descriptive study suggests that cognitive conflicts, although by no means considered to be causal or constitutive, may play an important role in social anxiety problems, at least, for some subjects. Thus, cognitive conflicts may or may not, play a role in subjects diagnosed with social phobia, however, it does seem likely. Also, for those whose conflicts can be identified in their grids, the degree of relevance of the conflicts might be different. Consequently, it seems reasonable to recommend the assessment of conflicts in order to identify those subjects for whom conflicts play a role in the problem. For these subjects, therapy should be directed at dealing with these conflicts and eventually resolving or dissolving them. Therapeutic procedures which address this aim have already been developed (Feixas, Saúl, Ávila, \& Sánchez, 2001; Feixas \& Saúl, in press).

\section{Some Data on Irritable Bowel Syndrome (IBS)}

There have been no previous studies on the content or structure of personal constructs in subjects with this diagnosis. IBS is a functional digestive disorder with multiple manifestations (e.g., abdominal pain and discomfort) for which no organic cause is found. To date, research shows that these subjects tend to have more psychological distress than other medical subjects: They present a high degree of comorbidity with psychiatric diagnosis, higher values in neuroticism and psychoticism, higher levels of stressful events, and a greater frequency of having experienced some kind of abuse (see Amigó, Fernández, \& Pérez, 1998; Benasayag, Feixas, \& Mearin, 2002; Fernández, 2003).

Our study (Benasayag, Feixas, Mearin, Saúl, \& Laso, 2004) compared a non-clinical group (63 subjects, with no psychiatric or digestive diagnosis known) with a small group ( $n=13 ; 12$ female, 1 male) of subjects diagnosed with IBS. Twelve out of thirteen IBS subjects also complied with the criteria for a psychiatric diagnosis using DSM-IV (Axis I); 7 with a diagnosis within the anxiety group, and 5 within the somatization disorders group.

The results, as summarized in Table 2, suggest that subjects with IBS present with many more implicative dilemmas and dilemmatic constructs than those in the normal group. Among IBS subjects, those with a diagnosis of somatization were the ones with a higher number of conflicts. Although no statistical analysis could be reasonably carried out because of the small number of cases, the magnitude of the differences clearly encourages more research with more cases, something we are presently working on.

With respect to the other grid measurements, we can appreciate the impressive differences shown in Table 2 (again, they need to be replicated with a bigger group and tested for statistical significance). The mean of the non-clinical group for the self-esteem measurement is almost identical to that of subjects with IBS diagnosed together with somatization disorders, but quite higher with respect to those diagnosed with anxiety disorders. Subjects diagnosed with both IBS and somatization show lower levels of differentiation (higher PVAFF scores [Percentage of Variance Accounted for by the First Factor]) and higher levels of polarization (extremity of ratings) than non-clinical subjects and also, more markedly, than those diagnosed with anxiety disorders.

These results suggest that subjects with IBS present with more conflicts in their construction system than a non-clinical

Table 1

Presence of Implicative Dilemmas and Dilemmatic Constructs in a Clinical Group of Patients Diagnosed with Social Phobia $(n=13)$ and a Non-Clinical $(N=224)$ Group (Díaz et al., 2001)

\begin{tabular}{llll}
\hline \multirow{2}{*}{ Presence of Dilemmatic Constructs } & \multicolumn{1}{c}{ Presence of Implicative Dilemmas } \\
\cline { 2 - 4 } & \multicolumn{1}{c}{ No ID } & With ID & Total \\
\hline No DC & NO CONFLICT & MODERATE CONFLICT & $31 \%$ Clinical \\
& $8 \%$ Clinical & $23 \%$ Clinical & $37 \%$ Non-clinical \\
With DC & $20 \%$ Non-clinical & $17 \%$ Non-clinical & $69 \%$ Clinical \\
& MODERATE CONFLICT & HIGH CONFLICT & $63 \%$ Non-clinical \\
Total & $23 \%$ Clinical & $46 \%$ Clinical & \\
& $43 \%$ Non-clinical & $20 \%$ Non-clinical & $69 \%$ Clinical \\
\hline
\end{tabular}


Table 2

Means and Standard Deviations (in Parentheses) of a IBS and a Non-Clinical Groups on a Selection of Grid Measures (Benasayag, Feixas, Mearin, Saúl, \& Laso, 2004)

\begin{tabular}{lcccc}
\hline & Non-clinical $n=63$ & SII $n=13$ & Somatization $n=7$ & Anxiety $n=5$ \\
\hline Number of implicative dilemmas & $3.22(5.21)$ & $12.62(14.74)$ & $17.57(16.50)$ & $8.20(11.67)$ \\
Number of dilemmatic constructs & $1.95(2.38)$ & $3.77(3.60)$ & $5.71(3.86)$ & $1.60(1.52)$ \\
Self-esteem (self-ideal correlation) & $0.42(0.33)$ & $0.31(0.38)$ & $0.40(0.24)$ & $0.11(0.52)$ \\
Differentiation (PVAFF) & $42.30(11.06)$ & $44.60(14.05)$ & $48.78(16.69)$ & $39.28(10.31)$ \\
Polarization & $23.47(13.88)$ & $28.83(20.04)$ & $35.87(18.38)$ & $19.86(22.49)$ \\
\hline
\end{tabular}

group. Even comparing them to the clinical group mentioned before, they seemed to be particularly prone to those conflicts (especially those diagnosed with somatization).

\section{The Therapy Process and its Influence in Resolving Dilemmas: Some Descriptive Data}

Feixas and Saul's (2003) preliminary report mentions another study with 87 clinical patients, including a re-analysis of 46 neurotic clients who were part of the sample used by Watson (1998). We examined the presence or absence of implicative dilemmas before and after therapy. From the data, it can be observed that subjects who do not present with implicative dilemmas at the start of therapy are unlikely to exhibit them when therapy ends; only $7.9 \%$ of the patients who did not exhibit implicative dilemmas at the start of therapy did so at the end. More than two thirds $(69.4 \%)$ of the group who presented with implicative dilemmas at the start of therapy did not present with implicative dilemmas at the end. Finally, less than one third (30.6\%) of subjects who presented with implicative dilemmas at the start of therapy, presented with implicative dilemmas at the end. These data suggest that psychological therapy, even when it is not specifically addressed towards resolving previously identified dilemmas, produces a statistically significant reduction in the number of implicative dilemmas in patients $(p<0.001$, using a chi-squared test reported in Feixas \& Saul, 2003).

Overall, we found that the percentage of patients who present with implicative dilemmas after the therapeutic process is $20.7 \%$. In comparison with the $34 \%$ found in the non-clinical group mentioned above, this is a lower profile of dilemmas for clients who completed a psychotherapy process. These data suggest that therapy decreases the number of implicative dilemmas to a level below that of the general population. So, psychotherapy does not merely return subjects to a normal level of conflict within their construction system, but actually serves to enhance or facilitate their construing to a more resolved level and helps them to be more dilemma free than average.

Obviously, more research is needed for exploring differences among psychotherapy approaches and their influence on decreasing the number of dilemmas one experiences. More importantly, research is needed to assess whether a brief therapy protocol focused on resolving previously identified dilemmas produces good outcomes, both in terms of symptom reduction and the dilemma's resolution.

\section{Conclusions}

Conceptualizing human problems in terms of cognitive conflicts or personal dilemmas is a way of understanding them from a constructivist perspective. Thus, by employing the symptom pole, the subject is validating other core constructs about his or her identity which are associated with it. Change to the opposite pole, the desired pole, would also imply abandoning part of his or her identity, which would involve a central change in the construction system of the client.

Implicative dilemmas can be identified using the Repertory Grid Technique, and each subject's grid assessed in terms of their presence (or not), as well as the proportion of dilemmas found. The results obtained, so far, from the Multi-Center Dilemma Project indicate that one third of a non-clinical group presents with implicative dilemmas, which suggests that dilemmas (even those detected using repertory grids) are part of the stress of "normal" life. However, they are more common (and more numerous) for subjects asking for help in psychotherapy services. This was especially evident for two clinical conditions investigated: social phobia and IBS. Further data with therapy clients show that psychological therapy, even when it is not specifically addressed towards resolving previously identified dilemmas, produces a statistically significant reduction in the number of implicative dilemmas the patient experiences.

These results suggest that more attention should be paid to implicative dilemmas, both as a personality characteristic, and in the therapy process. The presence of cognitive conflicts cuts across many clinical conditions and diagnostic categories. As far as we know, it cannot be considered the cause nor the consequence of any of them. But when conflicts are detected, our studies suggest that it would be convenient to address them in the therapy process. And so, clearly, a systematic assessment for exploring cognitive conflicts seems to be a reasonable recommendation for clinical research and practice. 


\section{References}

Amigó I., Fernández C., \& Pérez M. (1998). Manual de psicología de la salud. Madrid: Pirámide.

Bannister, D. (1960). Conceptual structure in thought-disordered schizophrenics. Journal of Mental Science, 106, 1230-1249.

Benasayag, R., Feixas, G., \& Mearín, F. (2002). Aspectos psicológicos en el Síndrome del Intestino Irritable. Gastroenterología Práctica, $11,14-17$.

Benasayag, R., Feixas, G., Mearin, F., Saúl, L. A., \& Laso, E. (2004). Conflictos cognitivos en el Síndrome del Intestino Irritable (SII): un estudio exploratorio. Revista Internacional de Psicología Clínica y de la Salud, 4, 105-119.

Botella, L., \& Feixas, G. (1998). La teoría de los constructos personales: aplicaciones a la práctica psicológica. Barcelona: Laertes.

Díaz, F., Feixas, G., Pellungrini, I., \& Saúl, L. A. (2001). Cuando relacionarse amenaza la identidad: la fobia social desde un enfoque constructivista. Boletín de Psicología, 72, 43-55.

Eiser, J. R. (1980). Cognitive social psychology. London: McGraw-Hill.

Feixas, G. (2002). El conflicto cognitivo. Manuscrito no publicado. Universitat de Barcelona.

Feixas, G. (2003). Subjective methods. In R. Fernández-Ballesteros (Ed.), The encyclopedia of psychological assessment (Vol. II, pp. 937-943). London: Sage.

Feixas, G., \& Cornejo, J. M. (1996). Manual de la técnica de rejilla mediante el programa RECORD ver. 2.0 (Segunda edición revisada). Barcelona: Paidós.

Feixas, G., Bach, L., y Laso, E. (in press). Factors affecting interpersonal construct differentiation when measured using the Repertory Grid. Journal of Constructivist Psychology.

Feixas, G., \& Cornejo, J. M. (2002). The GRIDCOR version 4.0 program for the analysis of repertory grid data. Computer program, available on the Internet: www.terapiacognitiva.net/record.

Feixas, G., López, J., Navarro, J., Tudela, M., \& Neimeyer, R.A. (1992). A study of reliability among grid measures. International Journal of Personal Construct Psychology, 5, 353-367.

Feixas, G., Sánchez, V., Laso, E., \& Gómez-Jarabo, G. (2002). La resistencia al cambio en psicoterapia: el papel de la reactancia, la construcción del sí mismo y el tipo de demanda. Análisis y Modificación de Conducta, 28, 235-286.

Feixas, G., \& Saúl, L. A (2002). Detection and analysis of cognitive conflicts: Implications for case formulation and the therapy process. In T. Scrimali \& L. Grimaldi (Eds.), Cognitive psychotherapy toward a new millennium (pp. 173-176). New York: Plenum Press.

Feixas, G., \& Saúl, L. A. (2003). Dilemma project internal report (Database, April, 2003). Unpublished document.

Feixas, G., \& Saúl, L. A. (in press). Resolution of dilemmas by personal construct psychotherapy. In D. Winter \& L. Viney (Eds.), Advances in personal construct psychotherapy. London: Whurr.

Feixas, G., Saúl, L. A., Avila-Espada, A., \& Sánchez, V. (2001). Implicaciones terapéuticas de los conflictos cognitivos. Revista Argentina de Clínica Psicológica, X, 5-13.
Feixas, G., Saúl, L. A., \& Sánchez, V. (2000). Detection and analysis of implicative dilemmas: Implications for the therapy process. In Joern W. Scheer (Ed.), The person in society Challenges to a constructivist theory (pp. 391-399). Giessen: Psychosozial-Verlag.

Feixas, G., \& Villegas, M. (2000). Constructivismo y psicoterapia $\left(3^{a}\right.$ ed. revisada). Bilbao: Desclée de Brouwer.

Fernández, C. (2003). Guía de tratamientos psicológicos eficaces en el síndrome del intestino irritable. In M. Pérez-Álvarez, J. R. Fernández-Hermida, C. Fernández-Rodríguez, \& I. AmigoVázquez (Eds.), Guía de tratamientos psicológicos eficaces II: Psicología de la salud. Madrid: Pirámide.

Festinger, L. (1957). A theory of cognitive dissonance. Standford, CA: Standford University Press.

Fransella, F. (1970). Stuttering: Not a symptom but a way of life. British Journal of Communication Disorders, 5, 22-29.

Fransella, F., Bell, R., \& Bannister, D. (2004). A manual for repertory grid technique ( $2^{\text {nd }}$ ed.). Chichester, UK: Wiley.

Heider, F. (1946). Attitudes and cognitive organization. Journal of Psychology, 21, 107-112.

López-Moliner, J., Navarro-Montes, J., Tudela-Mari, M., Feixas, G., \& Neimeyer, R. A. (1989, August). A comparison of methods of analysis of grid data. Paper presented at the Eighth International Congress on Personal Construct Psychology, Assisi, Italy.

Kegan, R. (1994). In over our heads: The mental demands of modern life. Cambridge, MA: Harvard University Press.

Kelly, G.A. (1955). The psychology of personal constructs $(2$ vols.). New York: Norton (reprinted by Routledge, London, 1991).

Kelly, G.A. (2001). Psicología de los constructos personales: Textos escogidos. Barcelona: Paidós.

Lucero, C., Feixas, G., \& Saúl, L. A. (2003). Constructos personales y perfil sintomático en la etapa de climaterio: un estudio exploratorio. Anuario de Psicología, 34, 371-383.

Neimeyer, R.A., \& Feixas, G. (1992). Cognitive assessment in depression: A comparison of some existing measures. European Journal of Psychological Assessment, 8, 47-56.

Piaget, J. (1975). L'equilibration des strctures cognitives: probléme central du développement. Paris: P.U.F.

Rivas, F., \& Marco, R. (1985). Evaluación conductual subjetiva: la técnica de rejilla. Valencia: Centro Editorial de Servicios y Publicaciones Universitarias.

Winter, D. A. (1988). Constructions in social skills training. In F. Fransella \& L. Thomas (Eds.), Experimenting with personal construct psychology (pp. 342-356). London: Routledge.

Winter, D. A. (1989). Resistance to therapy: Stubborn opposition or constructive choice? Paper presented at 3rd European Conference on Psychotherapy Research, Bern.

Received February 10, 2004 Revision received March 22, 2004 Accepted March 31, 2004 


\section{Apendix 1}

A Summary Description of the Repertory Grid Technique as Used to Investigate Interpersonal Construing

\section{Background}

Kelly (1955) created the Role Construct Repertory Test, or Reptest, and also its grid form, within the context of his Personal Construct Theory. Since then, it has evolved as complex and flexible methodology known as the Repertory Grid Technique (RGT) ${ }^{1}$ with a variety of formats and applications. The RGT is devised to assess the dimensions and structure of personal meaning, usually in the subject's own terms. Thus, it aims at grasping the way an individual (also groups and institutions) makes sense of him or herself and others. The RGT explores the structure and content of the construction systems, implicit theories or meaning structures with which people construct their experience, perceive and act.

\section{Administration Procedure}

The administration of the RGT designed to study interpersonal construing in individuals involves three stages (Feixas \& Cornejo, 1996) in the context of a structured interview. This process will be illustrated in the case of Teresa $^{2}$.

\section{ELEMENTS}

\section{CONSTRUCTS}

\begin{tabular}{|c|c|c|c|c|c|c|c|c|c|c|c|c|}
\hline 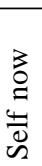 & 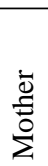 & 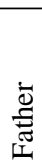 & 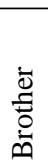 & 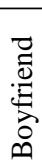 & 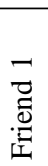 & 党 & 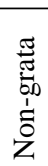 & $\frac{m}{\stackrel{0}{0}}$ & 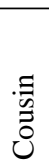 & 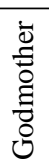 & 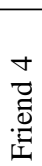 & 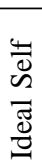 \\
\hline 1 & 1 & 5 & 2 & 7 & 3 & 6 & 2 & 6 & 4 & 3 & 2 & 7 \\
\hline 1 & 6 & 6 & 2 & 2 & 5 & 6 & 3 & 5 & 6 & 4 & 5 & 4 \\
\hline 2 & 2 & 6 & 2 & 4 & 5 & 6 & 5 & 2 & 3 & 4 & 5 & 5 \\
\hline 5 & 1 & 2 & 2 & 6 & 6 & 6 & 1 & 6 & 7 & 6 & 6 & 7 \\
\hline 6 & 2 & 1 & 1 & 4 & 3 & 6 & 1 & 7 & 3 & 4 & 2 & 7 \\
\hline 2 & 7 & 1 & 6 & 4 & 3 & 4 & 6 & 3 & 3 & 5 & 6 & 3 \\
\hline 2 & 6 & 6 & 6 & 1 & 5 & 4 & 7 & 4 & 2 & 2 & 5 & 1 \\
\hline 6 & 4 & 2 & 2 & 7 & 4 & 6 & 2 & 6 & 6 & 6 & 3 & 7 \\
\hline 2 & 2 & 6 & 7 & 2 & 3 & 5 & 7 & 3 & 3 & 2 & 2 & 2 \\
\hline 6 & 1 & 1 & 1 & 7 & 5 & 5 & 1 & 6 & 3 & 3 & 6 & 7 \\
\hline 1 & 5 & 7 & 7 & 1 & 4 & 5 & 7 & 1 & 4 & 3 & 4 & 1 \\
\hline 6 & 6 & 5 & 4 & 6 & 6 & 6 & 1 & 6 & 5 & 6 & 5 & 7 \\
\hline 5 & 4 & 4 & 2 & 6 & 5 & 5 & 1 & 6 & 6 & 5 & 4 & 7 \\
\hline 3 & 2 & 2 & 1 & 5 & 6 & 6 & 1 & 6 & 6 & 6 & 3 & 7 \\
\hline 6 & 3 & 1 & 2 & 5 & 2 & 4 & 2 & 7 & 6 & 6 & 5 & 6 \\
\hline 6 & 3 & 3 & 3 & 6 & 2 & 1 & 2 & 4 & 4 & 6 & 4 & 7 \\
\hline 5 & 2 & 2 & 1 & 4 & 2 & 4 & 1 & 6 & 3 & 5 & 2 & 7 \\
\hline 1 & 2 & 6 & 2 & 4 & 5 & 7 & 5 & 2 & 6 & 6 & 5 & 5 \\
\hline 1 & 2 & 6 & 3 & 6 & 3 & 7 & 6 & 1 & 3 & 3 & 3 & 6 \\
\hline 6 & 6 & 4 & 6 & 1 & 5 & 2 & 7 & 6 & 3 & 3 & 5 & 1 \\
\hline
\end{tabular}

1. Pessimistic

2. Self-demanding

3. Fearful

4. Lives to work

5. Imposes his/her wishes

6. Teasing

7. Appreciates others

8. Aggressive

9. Concerned about others

10. Avaricious

11. Sensitive

12. Cheeky

13. Hypocritical

14. Blackmailer

15. Appears stronger than is

16. Does not look after the friendship

17. Non Accessible

18. Introverted

19. Gets depressed easily

20. Tries to find the good in things
1. Optimistic

2. Takes it easy

3. Enterprising

4. Works to live

5. Tolerant with others

6. Touchy

7. Does not appreciate others

8. Calm

9. Selfish

10. Generous

11. Materialistic, superficial

12. Respectful

13. Sincere

14. Non blackmailer

15. Natural

16. Looks after the friendship

17. Accessible

18. Extroverted

19. Does not get depressed easily

20. Sees only the negative

1 very much so, 2 quite a lot, 3 a little, 4 middle point, 5 a little, 6 quite a lot, 7 very much so.

Figure 1. Teresa's pre-therapy Repertory Grid.

1 There are several manuals for this technique, see for example, Feixas and Cornejo, 1996; Fransella, Bell and Bannister, 2004; Rivas and Marco, 1985.

2 When Teresa, 22 years old, was seen by the second author (LAS) at the psychological services of the University of Salamanca, she was in the final year of her studies in chemical sciences. Although Teresa proves to be an excellent student, she reveals serious doubts about her self worth. She cries frequently, and has great difficulty in meeting others, even though she has a boyfriend who is extremely supportive. Teresa is anxiously hesitant about accepting a new job which would involve moving to another city $600 \mathrm{Km}$ away from home. 
Selection of elements. Normally, a set of 10-20 elements must be selected from the subject's world. Often, these elements represent various "role titles" of significant others (heading columns in the example shown in Figure 1) who play a part in the person's life (e.g., family members, employer, friends, a disliked figure) including his or her present self and the ideal self ("how I would like to be").

Construct elicitation. The individual is asked to concentrate on pre-selected groupings of two or three elements and to construe them in terms of their similarities and/or contrasts which requires the subject to provide the meaning dimensions that make these elements similar or different. In the example, Teresa is asked in which ways her parents are similar, to which she replies they "take it easy." Then, she is asked what would be the opposite of taking it easy, and she replies "self-demanding." Thus, the first construct is elicited and written in the rows of the grid table (as in Figure 1). With the same dyad of elements (father and mother), she is asked for more similarities and, then, for differences between them, to which she replies her mother is "pessimistic" while her father is more "optimistic," this being another construct to be added to the list. She is asked for more differences (or similarities) until she cannot come up with any others. Then, a new dyad of elements is selected (e.g., self now and mother) and the process is repeated until all elements appear at least once in the comparisons. There is a limit on the number of constructs to be elicited. The construct elicitation process ends whenever interviewer and subject consensually feel no more new constructs can appear (what is known as the "saturation point").

Rating the elements in terms of the constructs. The grid form implies that each construct (row) is applied to each element (column), usually employing a rating system (7point Likert-type scale). Thus, by applying (rating) all the constructs across the entire set of elements, a grid data matrix is created (see Figure 1).

\section{Analysis and interpretation}

The grid data matrix can be analyzed in a variety of ways ranging from qualitative appreciation of the nature and quality of the constructs used, to the statistical analysis of the data using cluster analysis or factor analytic methods. Finally, a number of cognitive measures can be extracted (e.g., differentiation, cognitive complexity, self-esteem, conflict analysis, extremity of ratings ${ }^{3}$ ) which can serve both to generate clinical hypotheses and to look for individual differences. A selection of these measures can be found in Appendix 2.

\section{Appendix 2}

A Selection of Measures Derived from Repertory Grids Using the RECORD/GRIDCOR ${ }^{4}$ Program Version 4.0

The Percentage of Variance Accounted for by the First Factor (PVAFF) is a factor analytic measure based on correspondence analysis. We consider it to be the best measure of cognitive complexity.

Bannister's (1962) Intensity is calculated from the sum of the squared values of the correlations of each construct with the rest of the constructs, averaged by the total number of constructs minus one. This process is repeated with each element, and the overall Intensity is calculated by averaging the intensity scores of constructs and elements.

Polarization is scored as the percentage of extreme ratings (e.g., 1 or 7 in a 7-point scale) in the grid matrix. The use of extreme ratings in grids with elicited constructs might reflect the subjective meaningfulness of specific constructs and elements. When taken as an overall measure (averaging extremity for the whole grid), it may indicate the degree of rigidity or pathology of the system (Neimeyer \& Feixas, 1992).

Self-Ideal differentiation is computed using the elements "self now" and "ideal self" product-moment correlation. It can be considered as a measure of self-esteem.

Self-Others Differentiation is calculated by computing the correlation between the "self now" and an artificial "others" element which is the result of averaging the scores of all but the "self now" and the "ideal self" elements. Low scores of self-others differentiation have been labeled «identification» by some authors and we consider that high scores can be considered an indication of "perceived social isolation."

Ideal-Others Differentiation. Although less frequently used in psychological literature, we consider the correlation between the "ideal self" and the "others" elements to be a measure of perceived adequacy of others. For example, while a high negative correlation can indicate that the subject is dissatisfied with the people that surround him/her, a positive correlation suggests a perception along the lines of «everyone is great.»

\footnotetext{
3 We have conducted various methodological studies about the validity and reliability of these measures (Feixas, Bach \& Laso, in press; Feixas, López-Moliner, Navarro-Montes, Tudela-Marí, \& Neimeyer, 1992)

4 RECORD is the Spanish name of the program for which a Manual was published, in Spanish, for version 2.0 (Feixas \& Cornejo, 1996). GRIDCOR is the name of the English version of this program. Version 4.0 of both programs and operative instructions for its use can be found on the Internet: www.terapiacognitiva.net/record
} 